\title{
Estimulação da consciência fonológica na educação infantil: prevenção de dificuldades na escrita
}

\author{
Magda Solange Vanzo Pestun \\ Leila Cristina Ferreira Omote \\ Déborah Cristina Málaga Barreto \\ Tiemi Matsuo
}

\begin{abstract}
Resumo
Consciência fonológica é uma competência metalinguística que possibilita o acesso consciente ao patamar fonológico da fala e a manipulação cognitiva das representações neste nível. Este estudo objetivou verificar se um programa de estimulação dessa habilidade no pré-III favoreceria a aquisição da escrita na $1^{\text {a }}$ série. Participaram do estudo 85 crianças alunas de escola pública. Procedimento: 1) pré-teste: avaliação do quociente intelectual, da consciência fonológica e da escrita; 2) elaboração do programa de estimulação e classificação das crianças em grupos: experimental (GE) e controle (GC), a partir de balanceamento estatístico; 3) aplicação do programa; 4) pós-teste: reavaliação da consciência fonológica e escrita. Os resultados indicaram que os dois grupos evoluíram em todas as variáveis do pré para o pós-teste. Qualitativamente, a evolução foi maior para o GE. Contudo, a diferença entre ambos não foi estatisticamente significante. Hipóteses: número insuficiente de sessões, número grande de crianças por grupo e/ou inexperiência das experimentadoras em práticas pedagógicas.
\end{abstract}

Palavras-chave: Consciência Fonológica, escrita, educação infantil.

\section{Phonemic awareness in children education: preventing difficulties in writing}

\begin{abstract}
Phonemic Awareness is the metalingüistic ability which enables the conscious approach to the phonemic level of speech and the most cognitive manipulation of these representations in this level. In this study we aim at verifying whether the phonemic stimulation in Kindergarten is predictive for writing acquisition in the 1st grade. Eighty-five children from public school participated in this study. We used the following procedure: 1) Pretest: intellectual evaluation, phonic and written conscious; 2) elaborating stimulus program and categorizing children in groups: experimental (GE) and a control (GC), statistically balanced; 3) program execution; 4) Post-test: re-evaluating the phonic and written conscious. The results indicate that both groups evolved in all the variables from the pre-test to the post-test. Qualitatively, the evolution was greater in the experimental group (GE). However, the difference between both was not significant. We suggest the following hypotheses: the number of sessions was insufficient; there were too many children per group; and/or the researchers were inexperienced in pedagogical practices.
\end{abstract}

Keywords: Phonological awareness, handwriting, early childhood education.

\section{Estímulo de la conciencia fonológica em la educación infantil: prevención de dificultades en la escritura}

\begin{abstract}
Resumen
Conciencia fonológica es una competencia metalingüística que posibilita el acceso consciente a la etapa fonológica del habla y a la manipulación cognitiva de las representaciones en este nivel. Este estudio tuvo como objetivo verificar si un programa de estimulación de esa habilidad en el jardín de infancia III favorecería a la adquisición de la escritura en el primer grado. Participaron del estudio 85 niñas, alumnas de escuela pública. Procedimiento: 1) pre-test: evaluación cociente intelectual, conciencia fonológica y escritura; 2) elaboración del programa de estimulación y clasificación de las niñas en grupos: experimental (GE) y controle (GC), a partir de balanceo estadístico; 3) aplicación del programa; 4) posttest: reevaluación de la conciencia fonológica y escritura. Los resultados indicaron que los dos grupos evolucionaron en todas las variables del pre para el post-test. Cualitativamente la evolución fue mayor para el GE. Sin embargo, la diferencia entre ambos no fue estadísticamente significativa. Hipótesis: número insuficiente de sesiones; número grande de niñas por grupo; y/o inexperiencia de las experimentadoras en prácticas pedagógicas.
\end{abstract}

Palabras clave: Conciencia Fonológica, escritura manual, educación infantil.

Revista Semestral da Associação Brasileira de Psicologia Escolar e Educacional, SP. * Volume 14, Número 1, Janeiro/Junho de 2010: 95-104. 


\section{Introdução}

... Vinte mil anos antes de nossa era, em Lascaux, homens traçam seus primeiros desenhos. Será preciso esperar 17 milênios para que se inicie uma das mais fabulosas facetas da história da humanidade - a escrita... (Jean, 2002, p.11).

Desde a Antiguidade, o homem sente a necessidade de registrar, de perpetuar os momentos históricos. Na pré-história, os homens faziam desenhos em pedras como sinais para transmitir mensagens, contudo essas informações só podiam ser interpretadas por membros daquela cultura que conheciam o significado de cada figura. Como transmitir os pensamentos, os sentimentos, os fatos de forma que integrantes de outras comunidades pudessem entendê-los? A necessidade da escrita, propriamente dita, torna-se imperativa!

Mas essa forma de comunicação criada pelo homem tem uma história longa, lenta e complexa. Começou a ser vista relativamente tarde na história de seu desenvolvimento, provavelmente muito tempo depois de a linguagem falada ter sido adquirida (Navas \& Santos, 2004; Zorzi, 2003).

Vale lembrar, segundo os autores acima citados, que o objetivo da escrita não é simplesmente o registro da fala, mas transmitir mensagens por meio de um sistema convencional que representa conteúdos linguísticos. É, portanto, uma forma de mediação linguística criada de acordo com as necessidades de uma sociedade com demandas culturais determinadas. Em outros termos, a linguagem falada tem raízes filogenéticas enquanto a linguagem escrita depende de variáveis ontogenéticas e sociogenéticas.

A estrutura de uma língua é representada por um sistema de escrita. O sistema de escrita do idioma português é o alfabético, criado aproximadamente em 1.000 a.C. pelos fenícios. O silabário fenício foi adaptado pelos gregos, que desenvolveram o alfabeto de 23 letras, muito usado pelos romanos durante o primeiro século a.C. e, desde então, o sistema vem sendo aprimorado.

O sistema alfabético é fonográfico, isto é, representa segmentos fonológicos, como sílabas e fonemas. Segundo Navas e Santos (2004), são as associações grafofonológicas e grafossemânticas que nos dão uma verdadeira compreensão do relacionamento entre os morfemas e a linguagem oral. Como os sistemas de escrita baseiam-se na linguagem oral, esse fato explica como a escrita e a ortografia funcionam. $\mathrm{O}$ poder do alfabeto para representar a língua, independente da complexidade de sua estrutura fonológica, é inegável, pois os leitores de sistemas alfabéticos podem ler palavras que nunca viram antes, já que elas são construídas a partir da combinação de fonemas e grafemas.

No português brasileiro, temos 26 grafemas e cerca de 40 representações fonológicas. Essas unidades formam uma "ponte" com a língua falada e se fundem em unidades linguísticas maiores, com função lexical e gramatical, provendo o acesso a todo o vocabulário de uma língua.
Como a escrita é uma habilidade criativa, construída a partir do alicerce alfabético, ela exige algumas habilidades precedentes que facilitarão essa complexa criação.

Uma dessas habilidades é a consciência fonológica, uma competência metalinguística que possibilita o acesso consciente ao patamar fonológico da fala e a manipulação cognitiva das representações neste nível. Portanto, envolve reflexão, análise e manipulação intencional de unidades que compõem a linguagem (palavras, sílabas, fonemas). Essa competência desenvolve-se à medida que as crianças conscientizam-se dessas unidades dentro de um continuum do grau nulo, a sensibilidade e a consciência (Cielo, 2002).

Importante salientar que esse continuum de complexidade de processamento significa que perceber palavras é mais fácil que perceber fonemas; que identificar rimas é mais fácil que excluir ou adicionar fonemas; e que segmentar fonemas é mais fácil que invertê-los.

Portanto, pré-escolares demonstram naturalmente algumas dessas habilidades, tais como perceber palavras que terminam com o mesmo som (rimas) ou que iniciam com o mesmo som (aliteração) e segmentar palavras em sílabas. No entanto, precisam ser ensinados a perceber fonemas nas palavras, haja vista que o fonema é a menor unidade sonora e não é naturalmente segmentada na linguagem oral e, desta forma, depende de experiências mais formalizadas.

De acordo com Liberman e cols. (conforme citado por Godoy, 2003), crianças de 4-5 anos possuem habilidades fonológicas silábicas, mas não fonêmicas, já que estas últimas são adquiridas no processo da aprendizagem da leitura e da escrita por volta dos seis anos de idade.

Quatro níveis de desenvolvimento da consciência fonológica são apontados:

1. Sensibilidade à rima e à aliteração: corresponde a uma etapa inicial, caracterizada pela descoberta, por parte da criança, de que determinadas palavras apresentam um mesmo conjunto de sons em seu princípio (aliteração) ou fim (rima). Implica uma capacidade para detectar estruturas sonoras semelhantes em diferentes palavras. Embora não seja considerada um conhecimento fonológico, acredita-se que tal noção possibilite um melhor desenvolvimento da consciência fonológica e, assim, auxilie a aprendizagem futura da escrita, especialmente, ao facilitar as estratégias de leitura por analogia;

2. Conhecimento silábico: corresponde a uma capacidade para segmentar e operar com as estruturas silábicas das palavras, que implica um processo de divisão da palavra em seus constituintes silábicos;

3. Conhecimento intrassilábico: envolve a compreensão de que as sílabas podem ser subdivididas em elementos menores do que elas mesmas e maiores do que um fonema; 
4. Conhecimento segmental: as palavras são compostas por um conjunto de segmentos sequenciados denominados fonemas.

Ao escrever, a criança precisa compreender que as letras, enquanto símbolos gráficos, correspondem a segmentos sonoros que não possuem significados em si mesmos.

Segundo Navas e Santos (2004), Zorzi (2003) e Pestun (2005), a relação entre a consciência fonológica no âmbito do fonema e a aquisição da leitura e da escrita é recíproca e bidirecional, ou seja, à medida que a consciência fonológica se desenvolve, ela facilita o aprendizado da leitura e da escrita que, por sua vez, propicia o estabelecimento da consciência fonológica. Portanto, a criança que é capaz de refletir sobre os sons da fala terá mais facilidade de associar esses sons às letras, adquirindo o princípio alfabético.

Desta forma, o desenvolvimento da consciência fonológica tem sido frequente e consistentemente relacionado ao sucesso da aprendizagem da leitura e da escrita.

Guimarães (2002), avaliou os níveis de consciência fonológica e consciência sintática, verificando a relação destas habilidades com o desempenho na leitura e na escrita de palavras isoladas. Os sujeitos com melhor desempenho em habilidades metalinguísticas (consciência fonológica e consciência sintática) apresentaram desempenho elevado em leitura e em escrita, ao mesmo tempo em que a aprendizagem da leitura alfabética contribuiu para o desenvolvimento da consciência fonológica.

Barrera e Maluf (2003) também investigaram a influência das habilidades metalinguísticas de consciência fonológica, lexical e sintática na aquisição da linguagem escrita em crianças de $1^{\text {a }}$ série do Ensino Fundamental. Os resultados demonstraram melhor desempenho em leitura e em escrita ao final do ano letivo em crianças que iniciaram o processo de alfabetização com níveis superiores em habilidades metalinguísticas.

Em muitos países, têm-se ensinado de forma explícita e sistemática a manipulação de fonemas na fase de alfabetização, diminuindo dificuldades em leitura e escrita e facilitando a melhor compreensão da relação fonema-grafema (A. G. S. Capovilla \& F. C. Capovilla, 2003).

No Brasil, Brito, Castro, Gouvêa e Silveira (2006), Paula, Mota e Keske-Soares (2005), Barreira e Maluf (2003), Cielo (2002), Godoy (2003), A. G. S. Capovilla e F. C. Capovilla (2000) e Maluf e Barrera (1997) defendem o ensino sistemático e explícito das relações grafofonêmicas para o desenvolvimento dos níveis de consciência fonológica no início da alfabetização a fim de facilitar a aquisição da linguagem escrita.

Dois estudos brasileiros importantes foram realizados de forma a verificar a eficácia de procedimentos de intervenção fônica na aquisição da leitura e escrita de crianças de escolas públicas e particulares (A. G. S. Capovilla \& F. C. Capovilla, 1998, 2000). Os resultados de ambos os estudos confirmaram que procedimentos para desenvolver a consciência fonológica e o ensino de correspondências grafofo- nêmicas podem auxiliar na aquisição da leitura e da escrita, principalmente no início da alfabetização.

O estudo de A. G. S. Capovilla e F. C. Capovilla (2000) verificou que alunos de primeira série de escola pública com baixo desempenho em consciência fonológica tiveram benefícios com treino de consciência fonológica e de correspondências grafofonêmicas, como síntese, segmentação, manipulação e transposição fonêmica, manipulação e transposição silábica. Esses benefícios estenderam-se às habilidades de leitura em voz alta de palavras e de pseudopalavras e escrita sob ditado de palavras e pseudopalavras, bem como ao conhecimento de letras, mas não a outras habilidades de processamento fonológico como memória de trabalho e acesso ao léxico, sugerindo que estas habilidades não são função da consciência fonológica.

Outro estudo, proposto por Paula e cols. (2005), verificou a influência da terapia em consciência fonológica nos processos de alfabetização por meio de atividades específicas e sistematizadas, como o ensino explícito da relação grafema-fonema, em crianças de $1^{\text {a }}$ série sem êxito na alfabetização. Os resultados apontaram que a terapia em consciência fonológica, associada ao ensino explícito das relações grafema-fonema, interferiu significativamente no processo de alfabetização. Houve um aumento do desempenho na habilidade de leitura após a terapia em consciência fonológica, demonstrando a existência de uma correlação entre leitura e consciência fonológica. Em consequência disso, a compreensão da leitura foi potencializada.

Cárnio e Santos (2005) também verificaram o efeito de um programa fonoaudiológico preventivo em linguagem oral e escrita no desenvolvimento da consciência fonológica. Os resultados encontrados sugerem eficácia do programa fonoaudiológico preventivo em linguagem oral e escrita para o desenvolvimento da consciência fonológica.

A. G. S. Capovilla e F. C. Capovilla (2004) investigaram os efeitos de um programa de tratamento de dificuldades fonológicas e de alfabetização nas habilidades de consciência fonológica, leitura em voz alta, escrita sob ditado, conhecimento de letras, codificação fonológica na memória de trabalho e acesso fonológico à memória de longo prazo com crianças de pré a $2^{\mathrm{a}}$ série. Os resultados demonstraram ganhos nas habilidades de consciência fonológica, leitura em voz alta e escrita sob ditado.

Britto e cols. (2006) realizaram uma pesquisa que avaliou a consciência fonológica de crianças no período da aquisição da linguagem escrita por meio do Teste de Consciência Fonológica - CONFIAS (Moojen, 2003) com o objetivo de comparar o desempenho de crianças em escrita e consciência fonológica após estimulação ou não. Verificou-se que as crianças que passaram pela intervenção apresentaram melhora nos resultados totais em consciência fonológica. Essas autoras descrevem que o desempenho do grupo estimulado foi significativamente maior em habilidades de consciência fonológica e desenvolvimento da escrita, apesar da observação de melhora nos resultados de ambos os grupos, o que aponta a importância da estimulação da consciência fonológica no período de apropriação da linguagem escrita. 
Pesquisas têm evidenciado que jogos e atividades metalinguísticas, como músicas, poemas e pistas letra-som, colaboram para o desenvolvimento da consciência fonológica e conhecimento alfabético (Snow e cols., Schneider e cols., Brennan \& Ireson, conforme citado por Craig, 2006). De maneira geral, o treino em consciência fonológica anterior à instrução formal em leitura facilita a leitura e o desenvolvimento ortográfico. $\mathrm{E}$ o benefício parece ser em longo prazo (Lundberg, conforme citado por Craig, 2006).

A sociedade atual - competitiva e exigente - prediz o sucesso profissional a partir do desempenho escolar e, como salienta Rotta (2006, p.113), "aprender tornou-se não só um diferencial, mas uma necessidade". Entre as habilidades acadêmicas consideradas de fundamental importância para o sucesso profissional, estão principalmente a leitura e a escrita.

A leitura refere-se à interpretação de sinais gráficos que uma comunidade convencionou utilizar para substituir os sinais linguísticos da fala. Envolve basicamente dois processos: decodificação e compreensão. A decodificação é o processo por meio do qual reconhecemos os símbolos escritos (gráfico e acústico), tarefa que exige atenção. Após o reconhecimento, é necessário converter os símbolos gráficos em representações fonológicas, o que possibilita o reconhecimento da palavra. O reconhecimento das palavras e identificação de referentes possibilita a compreensão (Rotta \& Pedroso, 2006).

A escrita, por sua vez, pode ser considerada um conjunto de processos de conceituação e lexicalização. Um aspecto central do desenvolvimento da escrita é a conversão fonema/grafema e, em seguida, a aquisição da ortografia e a constituição de uma memória grafêmica.

Segundo artigo assinado por Cláudia Costin - vicepresidente da Fundação Victor Civita e ex-ministra da Administração Federal e Reforma do Estado - publicado na Folha de Londrina de 23/10/2008, sob o título "A educação de crianças e jovens", Londrina concentra as melhores escolas públicas do Paraná de acordo com MEC - 2007. Mesmo assim, está longe do ideal. Para a $4^{\mathrm{a}}$ série, a meta era atingir nota 4,7 e a alcançada foi 4,9. Das 146 escolas municipais, $41(28 \%)$ ficaram abaixo da média. Além disso, a pior nota do Estado pertence a uma escola da cidade (Costin, 2008).

Tendo esse panorama como figura de fundo, objetivamos estudar e identificar algumas medidas que poderiam melhorar esse quadro e propiciar às crianças londrinenses um desenvolvimento global adequado. De forma mais específica, nossa meta foi verificar:

- Se um programa de estimulação de habilidades metalinguísticas, aplicado no pré III de modo sistemático, desenvolveria a consciência fonológica;

- Se haveria correlação entre consciência fonológica e escrita de palavras.

\section{Método}

Esse estudo integra um projeto de extensão e pesquisa intitulado "Transtornos da Aprendizagem: avaliação, intervenção, investigação e prevenção" e constitui a primeira parte do trabalho de prevenção realizada no ano de 2008. Para esse ano, cinco etapas foram propostas e executadas:

$1^{\mathrm{a}}$ ) avaliação intelectual e cognitiva (habilidades metalinguísticas e escrita de palavras) de 88 crianças matriculadas no pré III em uma escola pública de Londrina, no ano de 2008;

$2^{\mathrm{a}}$ ) elaboração de um programa de atividades metalinguísticas que priorizava o desenvolvimento da consciência fonológica a ser aplicado às crianças do grupo experimental;

$3^{\text {a) }}$ aplicação do programa de intervenção;

$4^{\text {a) }}$ reavaliação cognitiva das 88 crianças;

$5^{\text {a) }}$ análise dos resultados obtidos no ano de 2008.

\section{Participantes}

A amostra dessa primeira parte do projeto foi constituída de 88 crianças, sendo 46 do sexo masculino e 42 do sexo feminino, com idade média de 67,3 meses ( $s d=3,33$ ) e alunos do pré III de uma escola municipal da zona sul da cidade de Londrina. Todas as crianças apresentavam condição socioeconômica baixa e foram autorizadas por seus pais a participarem do estudo mediante assinatura do Termo de Consentimento Livre e Esclarecido.

As atividades de avaliação e de intervenção foram realizadas na própria escola em horário regular de aulas e conduzidas por cinco profissionais: duas psicólogas graduadas, inseridas no Programa de Prestação de Serviço Voluntário da Universidade Estadual de Londrina (UEL), uma aluna do quinto ano de psicologia da UEL, uma psicopedagoga da Secretaria de Educação do Município de Londrina e a autora do artigo, como coordenadora do estudo.

\section{Instrumentos e materiais}

Os instrumentos empregados para as fases de avaliação foram:

1. Escala Wechsler de Inteligência para Crianças - WISC-III (Wechsler, 2002), adaptada e padronizada para a população brasileira. É um instrumento clínico, de aplicação individual, que tem por objetivo aferir a capacidade intelectual de crianças entre seis anos e 16 anos e 11 meses. Consiste em 13 subtestes divididos em dois grupos identificados como verbal e não verbal ou de execução. O desempenho avaliado nos vários subtestes é resumido em três medidas compostas: QI verbal, QI de execução e QI total. Além desses escores, o WISC-III oferece quatro escores em índices fatoriais: compreensão verbal $(\mathrm{CV})$, organização perceptual $(\mathrm{OP})$, resistência à distração $(\mathrm{RD})$ e velocidade de processamento (VP). Foi aplicada com o propósito de excluir crianças com atraso intelectual.

2. CONFIAS - Consciência Fonológica: Instrumento de Avaliação Sequencial (Moojen, 2003). Esta prova objetiva avaliar as diferentes habilidades cognitivas que envolvem a consciência fonológica. As tarefas abrangem dois níveis: a) Nível da Sílaba, composto por oito questões, sendo cada uma delas com dois itens de treino e quatro itens de 
teste, e uma questão com dois itens de treino e oito itens de teste, totalizando pontuação máxima de 40 acertos; b) Nível do Fonema, composto por seis questões com dois itens de treino e quatro itens de teste e uma questão com dois itens de treino e seis itens de teste, totalizando pontuação máxima de 30 acertos. Os acertos e erros dos sujeitos experimentais e controles foram registrados em protocolos específicos do próprio instrumento para posterior análise, tendo por base a pontuação esperada para crianças alfabetizadas, sendo 70 acertos o máximo possível.

3. Quatro palavras e uma frase. Quatro palavras (uma monossílaba, uma dissílaba, uma trissílaba e outra polissílaba) que não pertencem ao repertório usual de cartilhas, mas fazem parte do campo de conhecimento das crianças e pertencem a um mesmo grupo semântico. Após as quatro palavras serem escritas, o ditado foi finalizado com uma frase na qual estava inserida uma das palavras ditadas anteriormente. A prova tem por objetivo verificar a hipótese de escrita elaborada pela criança, uma vez que o processo de construção da concepção de escrita passa por diferentes níveis. Para Ferreiro e Teberosky (1991), a criança, durante o período de contato com os sinais gráficos, passa por estágios de evolução com características marcantes que podem ser agrupados em quatro grandes níveis: pré-silábico, silábico, silábico-alfabético e alfabético, que são descritos concisamente no procedimento (tabela de pontuação). As palavras ditadas no pré-teste foram: boi, gato, cavalo e borboleta; no pós-teste, foram: pão, bolo, bolacha e gelatina.

4. Papel Sulfite, lápis preto e lápis colorido.

5. Cronômetro.

\section{Procedimento}

De acordo com Almeida (2003), este estudo caracteriza-se como uma pesquisa-ação, uma vez que seu objetivo é verificar a eficácia de uma proposta de intervenção que, de modo geral, visa promover melhora na qualidade de aprendizado de crianças pré-escolares. Caracteriza-se ainda como uma pesquisa experimental de grupo, com pré e pós-teste. A variável dependente (VD) refere-se ao comportamento que está sendo medido, nesta pesquisa, o desempenho em consciência fonológica e escrita. A variável independente (VI) refere-se ao tratamento ou procedimento em estudo (intervenção em consciência fonológica). Quando um delineamento é capaz de demonstrar que a manipulação da VI resulta em mudanças na VD, a tentativa de relação causa/ efeito pode ser assumida. Essa união é chamada de relacionamento funcional (Alberto \& Troutman; Mcguigan; Lakatos \& Marconi, conforme citado por Almeida, 2003).

O procedimento constou de quatro etapas:

Etapa 1 (avaliação pré-teste) - realizada de fevereiro a abril de 2008. As 88 crianças foram avaliadas de forma individual em quatro sessões de 30 minutos quanto ao desempenho intelectual e cognitivo por meio dos testes WISC-III e CONFIAS e prova de escrita de quatro palavras e uma frase. As avaliações de potencial intelectual e habilidades metalinguísticas foram realizadas pelas duas psicólogas graduadas e a avaliação de escrita, pela psicopedagoga da prefeitura. As duas primeiras sessões foram dedicadas à aplicação do WISC-III, seguindo procedimento padrão recomendado no manual. A terceira e a quarta sessões foram dedicadas à aplicação do CONFIAS e à escrita de quatro palavras e uma frase. Para o CONFIAS, foram seguidas as recomendações sobre o procedimento de aplicação segundo manual. Quanto à escrita de quatro palavras e uma frase, foram seguidas as recomendações de Ferreiro e Teberosky (1991). As respostas foram registradas em protocolos-padrão para análise posterior. A análise dos resultados obtidos no WISC-III e CONFIAS seguiram as normas dos próprios testes. Quanto à prova de escrita de quatro palavras e uma frase, estabelecemos os critérios descritos na Tabela 1.

Os resultados obtidos foram tratados por meio de análise estatística não paramétrica, classificando as crianças

Tabela 1. Critérios estabelecidos para a aplicação e avaliação da prova de escrita de quatro palavras e uma frase segundo Ferreiro e Teberosky (1991).

\begin{tabular}{c|c|c|c}
\hline & \multicolumn{2}{c}{ AVALIAÇÃo DA ESCRITA (Ferreiro \& Teberosky, 1991) } \\
\hline Número de pontos & Nível da escrita & \multicolumn{1}{c}{ Características } \\
\hline 4 & Nível alfabético & $\begin{array}{l}\text { Cada um dos caracteres da escrita corresponde a } \\
\text { valores sonoros menores que a sílaba. Não atende à } \\
\text { norma ortográfica. }\end{array}$ \\
\hline 3 & $\begin{array}{c}\text { Nível silábico- } \\
\text { alfabético }\end{array}$ & $\begin{array}{l}\text { Manifestação alternante do valor silábico ou fonético para } \\
\text { as diferentes letras. }\end{array}$ \\
\hline 1 & Nível silábico & $\begin{array}{l}\text { Cada letra vale por uma sílaba. Escrita com ou sem o } \\
\text { predomínio do valor sonoro convencional. }\end{array}$ \\
\hline 0 & Nível pré- & $\begin{array}{l}\text { Marcado por escritas que não apresentam nenhum tipo } \\
\text { de correspondência sonora, isto é, sem relação com } \\
\text { grafia e som. }\end{array}$ \\
\hline & silábico & \begin{tabular}{l} 
Somente rabiscos. \\
\hline
\end{tabular} &
\end{tabular}


em dois grupos a partir do desempenho em consciência fonológica e potencial intelectual: um com desempenho acima da mediana e outro com desempenho abaixo da mediana. A partir dessa classificação, houve um balanceamento estatístico que redistribuiu as crianças em dois novos grupos: experimental e controle. Cada um desses grupos foi constituído de crianças com desempenho acima e abaixo da mediana.

Etapa 2 (elaboração do programa de estimulação da consciência fonológica) - realizada de maio a julho de 2008. As duas psicólogas graduadas, a psicopedagoga e a autora deste artigo elaboraram um programa de estimulação das habilidades de consciência fonológica a ser realizado em 35 encontros de uma hora cada. O programa envolveu tarefas de consciência de palavras, identificação de rimas e aliterações e consciência silábica e fonêmica. Os exercícios, em sua maioria, foram extraídos daqueles propostos por A. G. S. Capovilla e F. C. Capovilla (2002) e Almeida e Duarte (2003).

Etapa 3 (implementação do programa de estimulação) - realizada de julho a outubro de 2008. Nessa fase, houve duas alterações na proposta inicial. A primeira, decorrente do desligamento da pesquisa de uma das psicólogas graduadas, fez com que a coordenadora do projeto decidisse pela inserção de uma aluna estagiária de psicologia, com experiência na área, como substituta. A segunda foi a inserção de uma professora da própria escola na pesquisa, com o objetivo de auxiliar a psicóloga graduada no controle das crianças em sala de aula durante a aplicação do procedimento de intervenção. As 44 crianças do grupo experimental (GE) foram divididas mediante balanceamento estatístico das características básicas em dois subgrupos de 22 alunos cada. Cada subgrupo foi assistido duas vezes por semana em encontros de 60 minutos cada um. As avaliações das atividades realizadas em cada encontro, bem como qualquer ocorrência, eram registradas em protocolo elaborado pelas pesquisadoras. As 44 crianças do grupo controle permaneceram em outra sala de aula, desenvolvendo atividades lúdicas com as duas professoras titulares.

Etapa 4 (reavaliação de todas as crianças - experimental e controle - pós-teste) - realizada em novembro e dezembro de 2008. Três crianças haviam solicitado transferência de escola durante o ano letivo e, portanto, somente 85 crianças foram reavaliadas quanto à consciência fonológica por meio do CONFIAS e escrita de quatro palavras e uma frase. Participaram dessa etapa de reavaliação somente a psicóloga graduada e a psicopedagoga. Os dados coletados foram analisados por meio de estatística não paramétrica. $O$ teste de qui-quadrado foi empregado para avaliar a homogeneidade da distribuição nos grupos de estudo e o teste de Mann-Whitney para comparar os grupos por meio das VDs.

\section{Resultados e discussão}

O estudo foi iniciado com 88 crianças matriculadas no pré III, no ano de 2008, em uma escola municipal da região sul da cidade de Londrina e concluído com 85 , devido à transferência de três alunos no decorrer do ano letivo.

As variáveis para análise foram descritas com a média \pm desvio padrão () e a mediana (Md) com valores mínimo (Min) e máximo (Max).

As diferenças das mensurações iniciais e finais foram avaliadas pela diferença entre a medida final e inicial e a razão entre medida final e inicial. Aplicou-se o teste de MannWhitney com as seguintes hipóteses nulas:

- Diferença entre as avaliações final e inicial $\mathrm{HO}$ : diferença média $=0$ ( $\mu$ final $-\mu$ inicial $=0 \rightarrow \mu$ final $=\mu$ inicial $)$

- Razão entre as avaliações final e inicial HO: razão média $=1$ ( $\mu$ final $/ \mu$ inicial $=1 \rightarrow \mu$ final $=\mu$ inicial $)$

Tabela 2. Caracterização da amostra em estudo (quociente intelectual total - QIT, idade e sexo).

\begin{tabular}{l|c|c|c}
\hline \multicolumn{1}{c|}{ Variável } & Controle (GC) & Experimental(GE) & Teste (Valor P) \\
\hline QIT & 44 & 44 & \\
$N^{a}$ & $86(76-120)$ & $85(75-116)$ & $U=0,078(p=0,7795)$ \\
Md (Min-Max) & & & \\
\hline Idade & 44 & 44 & \\
N & $67(62-73)$ & $67(62-73)$ & $U=0,051(p=0,8209)$ \\
Md (Min-Max) & & & \\
\hline Sexo & $20(50,0 \%)$ & $20(50,0 \%)$ & $\chi 2=0,00(p=1,0000)$ \\
Feminino & $24(50,0 \%)$ & $24(50,0 \%)$ & \\
Masculino & & \\
\hline
\end{tabular}

a - Número de crianças 
De agosto a outubro de 2008, foram realizadas 29 sessões de 60 minutos cada. Não foi possível realizar as 35 sessões propostas inicialmente devido aos recessos escolares ocorridos no período. Assim, as atividades que envolviam o ensino dos fonemas não foram trabalhadas. No decorrer das sessões de intervenção, foi observado que algumas variáveis interferiram na produtividade do programa proposto. Uma delas foi o número de crianças $(n=22)$ em cada sala de intervenção, o que dificultou o controle da disciplina e aplicação de alguns exercícios que exigiam respostas individuais. Outra variável desfavorável foi a inexperiência da psicóloga graduada e da estagiária de psicologia em práticas pedagógicas, havendo a necessidade de auxílio de uma professora do quadro de docentes da escola para atuar no controle das crianças.

A Tabela 2 fornece a caracterização da amostra em estudo e descreve a distribuição dos participantes entre os grupos controle (GC) e experimental (GE) quanto ao quociente intelectual total (QIT), idade e sexo.

Como pode ser observada, a distribuição por gênero dos alunos nos grupos controle (GC) e experimental (GE) foi homogênea $(p=1,000)$.

Os resultados do pré e do pós-teste nas provas do CONFIAS e nas provas de escrita, bem como as diferenças entre o pós e o pré-teste para os grupos controle (GC) e experimental (GE), estão descritos na Tabela 3.

No teste CONFIAS, os dois grupos (GC e GE) evoluíram em todas as variáveis medidas do pré para o pós-teste, no entanto a evolução foi maior para as crianças do grupo experimental, tanto para sílaba como para fonema. Contudo a diferença entre os dois grupos não foi estatisticamente significativa $(p>0,05)$.

No pré-teste, não houve diferença entre os grupos controle e experimental em sílabas ( $p=0,8273)$, em fonemas $(p=0,8394)$ e em escrita $(p=0,7773)$, o que demonstra a homogeneidade dos grupos.

Interessante observar que o desempenho das crianças em todas as provas do CONFIAS, avaliado no pré-teste, ficou abaixo do esperado para crianças na fase pré-silábica, segundo escores obtidos na validação do teste CONFIAS ( $\pm 23,52$ para sílabas; 8,28 para fonemas e 31,8 para total). Uma hipótese levantada para o fraco desempenho das crianças de nossa amostra na avaliação pré-teste pode ser o baixo nível socioeconômico, somado à ausência de escolarização formal antes do pré III. Pestun (2005) e Da Silva (2004) verificaram a influência da condição sociocultural e econômica nas aquisições metalinguísticas e constataram déficit nessa habilidade em crianças pertencentes às classes menos favorecidas. Os resultados obtidos nesse estudo indicaram que a carência em estimulação da linguagem oral poderia ser a responsável por tal desempenho, pois crianças que frequentavam ensino pré-escolar havia mais de dois anos e cujos pais apresentavam grau de instrução superior demonstraram melhores resultados em habilidades metalinguísticas quando comparadas às crianças que iniciaram sua escolarização somente no pré III e cujos pais tinham em média quatro anos de estudo. Segundo Morais, Mousty e Kolinsky (1998), pais que apresentam poucos anos de escolarização, leem menos para seus filhos e fazem poucos jogos de linguagem com eles, o que desfavorece o desenvolvimento das habilidades metalinguísticas.

No pós-teste, podemos observar evolução de ambos os grupos em todas as modalidades trabalhadas e avaliadas, sendo que o GE evoluiu mais que o GC em todas as medidas do CONFIAS. Contudo a diferença de desempenho entre os grupos não foi significativa $(p=0,1532)$. Interessante que somente o GE atingiu o nível pré-silábico na modalidade sílabas $(23,4 \pm 4,8)$ - trabalhadas nas sessões de intervenção. Seria efeito do programa de estimulação? Em fonemas, os dois grupos atingiram o mesmo nível $(8,86 \pm 4,70$ para o GE e 8,40 $\pm 5,20$ para o GC). Como a modalidade fonemas não foi trabalhada durante a aplicação do programa de estimulação, seria a instrução formal responsável por esse resultado? Essas variáveis deverão ser melhor controladas em 2009.

Quanto à não diferença estatisticamente significativa de ganho entre os grupos, duas hipóteses que podem explicar esse resultado foram levantadas:

$\left.1^{a}\right)$ O número de sessões de intervenção pode ter sido insuficiente para desenvolver uma capacidade cognitiva que está estritamente relacionada à própria compreensão da linguagem oral. Acreditamos que as atividades de conscientização fonológica para crianças nessa faixa etária, oriundas de classes sociais menos favorecidas e com inexperiência escolar, deveriam fazer parte das atividades rotineiras e não somente de forma esporádica.

$2^{a}$ ) O despreparo das psicólogas em práticas pedagógicas pode ter produzido dificuldades para manter as crianças atentas e envolvidas nos exercícios.

Essas duas variáveis podem ter contribuído para os resultados obtidos.

\section{Conclusão}

O presente estudo teve por objetivo verificar se um programa de estimulação de uma habilidade metalinguística (consciência fonológica) aplicado de modo sistemático no pré III desenvolveria essa habilidade e se haveria correlação entre a consciência fonológica e a escrita.

Os resultados obtidos revelaram ganhos em consciência silábica, consciência fonêmica e em escrita em ambos os grupos (GE e GC). Apesar do GE ter evoluído mais que o GC em todas as modalidades, a diferença de ganho entre os grupos não foi estatisticamente significativa. Acreditamos que o tempo de exposição das crianças do GE ao programa de estimulação foi insuficiente para um avanço maior.

Como a aquisição da consciência linguística é gradual e depende tanto do desenvolvimento e amadurecimento biológico quanto das constantes trocas com o meio ou o contexto (Cielo, 2002), acreditamos que um trabalho sistemático de estimulação das capacidades metalinguísticas deva estar presente desde os primeiros anos da educação infantil com o objetivo de conduzir os alunos a um eficaz aprendizado do princípio alfabético que desenvolva plenamente habilidades mais complexas de leitura e escrita. 
Tabela 3. Resultados pré e do pós-teste nas provas do CONFIAS e nas provas de escrita para os grupos controle e experimental (Valores medianos, mínimo e máximo das variáveis - Md (Min-Max), e teste de Mann-Whitney)

\begin{tabular}{|c|c|c|c|}
\hline \multicolumn{4}{|c|}{ PRÉ -TESTE a } \\
\hline Variáveis & Controle (GC) & Experimental (GE) & Teste (valor $p$ ) \\
\hline \multicolumn{4}{|c|}{ Sílabas CONFIAS(1) } \\
\hline $\mathrm{N}$ & $44^{c}$ & $44^{c}$ & \\
\hline Md (Min-Max) & $13(6-28)$ & $13(8-21)$ & $U=0,047(p=0,8273)$ \\
\hline \multicolumn{4}{|c|}{ Fonema CONFIAS (1) } \\
\hline $\mathrm{N}$ & 44 & 44 & \\
\hline Md (Min-Max) & $5(2-10)$ & $4(2-11)$ & $U=0,041(p=0,8394)$ \\
\hline \multicolumn{4}{|l|}{ Total CONFIAS(1) } \\
\hline $\mathrm{N}$ & 44 & 44 & \\
\hline Md (Min-Max) & $18(9-36)$ & $18(11-31)$ & $U=0,001(p=0,9800)$ \\
\hline \multicolumn{4}{|l|}{ Escrita (1) } \\
\hline $\mathrm{N}$ & 44 & 44 & \\
\hline Md (Min-Max) & $1(0-3)$ & $1(0-2)$ & $U=0,080(p=0,7773)$ \\
\hline \multicolumn{4}{|c|}{ PÓS-TESTE b } \\
\hline Variáveis & Controle (GC) & Experimental (GE) & Teste (valor $\mathrm{p}$ ) \\
\hline \multicolumn{4}{|c|}{ Sílabas CONFIAS (2) } \\
\hline $\mathrm{N}$ & $42^{d}$ & $43^{d}$ & \\
\hline Md (Min-Max) & $24(12-39)$ & $27(16-37)$ & $U=2,533(p=0,1115)$ \\
\hline \multicolumn{4}{|c|}{ Fonema CONFIAS (2) } \\
\hline $\mathrm{N}$ & 42 & 43 & \\
\hline Md (Min-Max) & $7(3-27)$ & $8(2-24)$ & $\mathrm{U}=0,697(\mathrm{p}=0,4037)$ \\
\hline \multicolumn{4}{|c|}{ Total CONFIAS (2) } \\
\hline $\mathrm{N}$ & 42 & 43 & \\
\hline Md (Min-Max) & $28(17-66)$ & $30(22-58)$ & $U=2,903(p=0,0884)$ \\
\hline \multicolumn{4}{|l|}{ Escrita (2) } \\
\hline $\mathrm{N}$ & 42 & 43 & \\
\hline Md (Min-Max) & $1(1-4)$ & $2(1-4)$ & $U=0,027(p=0,8700)$ \\
\hline
\end{tabular}

DIFERENÇA ENTRE PÓS E PRÉ-TESTE

\begin{tabular}{c|c|c|c}
\hline Variáveis & Controle (GC) & Experimental (GE) & Teste (valor $\mathbf{p})$ \\
\hline Sílabas CONFIAS (2-1)/1 & & 42 & \\
N & 42 & & \\
Md (Min-Max) & $0,626(0,0-2,0)$ & $0,727(0,17-2,5)$ & $\mathrm{U}=2,408(\mathrm{p}=0,1207)$ \\
\hline Fonema CONFIAS (2-1)/1 & 42 & 43 & \\
N & $0,58(-0,56$ a 3,67$)$ & $0,80(-0,50$ a 6,00$)$ & $\mathrm{U}=0,061(\mathrm{p}=0,8052)$ \\
Md (Min-Max) & 42 & 43 & \\
Total CONFIAS (2-1)/1 & $0,694(-0,04$ a 1,80) & $0,765(0,04$ a 1,92) & $\mathrm{U}=2,041(\mathrm{p}=0,1532)$ \\
\hline
\end{tabular}

a - Primeira avaliação: fevereiro e março de 2008.

b - Segunda avaliação: outubro e novembro de 2008.

c - O estudo foi iniciado com 88 crianças (44 GC e $44 \mathrm{GE}$ ).

d - O estudo foi concluído com 85 crianças (42 GC e 43 GE). 
Sendo uma das defensoras da existência de uma relação recíproca e bidirecional entre a aquisição de leitura e escrita e o desenvolvimento da consciência fonológica, acreditamos que o processo de alfabetização irá contribuir e favorecer para que os aprendizes deste estudo foquem a atenção nos aspectos sonoros e segmentais da linguagem oral - como a consciência fonêmica.

Acreditamos também que os efeitos deste trabalho de estimulação possam ser melhor avaliados no decorrer da $1^{a}$ série do Ensino Fundamental, com realização de mais um pós-teste. Esperamos observar e analisar se os resultados da conscientização fonológica obtidos no pré III poderão predizer a leitura contextual e escrita um ano depois.

Pensamos também que um programa de capacitação de professores de Educação Infantil seria promissor.

Portanto, esse estudo continua!

\section{Referências}

Almeida, M. A. (2003). Metodologia de delineamentos de pesquisa experimental intra-sujeitos. Em M. C. Marquezine, M. A Almeida \& S. Omote (Orgs.), Colóquios sobre pesquisa em educação especial (pp. 63-99). Londrina: EDUEL.

Almeida, E. C., \& Duarte, P. M. (2003). Consciência Fonológica: atividades práticas. Rio de Janeiro: Revinter.

Barrera, S. D., \& Maluf, M. R. (2003). Consciência metalinguística e alfabetização: Um estudo com crianças da primeira série do ensino fundamental. Psicologia: Reflexão e Crítica, 16(3), 491-502.

Britto, D. B. O, Castro, C. D, Gouvêa, F. G., \&. Silveira, O. S. (2006). A importância da consciência fonológica no processo de aquisição e desenvolvimento da linguagem escrita. Revista Brasileira de Fonoaudiologia, 11(3), 142-150.

Capovilla, A. G. S., \& Capovilla, F. C. (1998). Prova de Consciência Fonológica: desenvolvimento de dez habilidades da pré-escola à segunda série. Temas sobre Desenvolvimento, 7(37), 14-20.

Capovilla, A. G. S., \& Capovilla, F. C. (2000). Efeitos do treino da consciência fonológica em crianças com baixo nível sócioeconômico. Psicologia: Reflexão e Crítica, 13(1), 7-24.

Capovilla, A. G. S., \& Capovilla, F. C. (2002). Alfabetização: método fônico. São Paulo: Memnon.

Capovilla, A. G. S., \& Capovilla, F. C. (2003). Comparando métodos de alfabetização: evidência da superioridade do método fônico em relação ao método global. Em M. C. Marquezine, M. A. Almeida \& E. D. Tanaka. (Orgs.), Leitura, escrita e comunicação no contexto da educação especial (pp. 1-28). Londrina: EDUEL.

Capovilla, A. G. S., \& Capovilla, F. C. (2004). Alfabetização: método fônico. São Paulo: Memnon.
Cárnio, M. S., \& Santos, D. (2005, Maio/Agosto). Evolução da consciência fonológica em alunos de ensino fundamental. PróFono: Revista de Atualização Científica, 17(2), 195-200.

Cielo, C. A. (2002, Setembro/Dezembro). Habilidades em consciência fonológica em crianças de 4 a 8 anos de idade. Pró-fono: Revista de Atualização Científica, 14(13), 301-312.

Costin, C. (2008, 10 de outubro). A educação de crianças e jovens. Folha de Londrina, p.7.

Craig, S. A. (2006). The effects of an adapted interactive writing intervention on kindergarten children's phonological awareness, spelling, and early reading development: a contextualized approach to instruction. Journal of Educational Psychology, 98(4), 714-731.

Da Silva, V. F. (2004). A influência sócio-cultural e econômica nas aquisições das habilidades metalinguísticas. Monografia, Psicologia aplicada à educação, Universidade Estadual de Londrina, Londrina, Paraná.

Ferreiro, E., \& Teberosky, A. (1991). A psicogênese da língua escrita. Porto Alegre: Artes Médicas.

Godoy, D. M. A. (2003, Setembro/Dezembro). O papel da consciência fonológica no processo de alfabetização. Pró-Fono: Revista de Atualização Científica, 15(3), 241-250.

Guimarães, S. R. K. (2002, Setembro/Dezembro). Dificuldades no desenvolvimento da lectoescrita: o papel das habilidades metalinguísticas. Psicologia: Teoria e Pesquisa, 18(3), 247-259.

Jean, G. (2002). A escrita - memória dos homens. Rio de Janeiro: Objetiva.

Maluf, M. R., \& Barrera, S. D. (1997). Consciência fonológica e linguagem escrita em pré-escolares. Psicologia: Reflexão e Crítica, 10(1), 125-145.

Moojen, S. (Coord.). (2003). CONFIAS - Consciência Fonológica: instrumento de avaliação sequencial. São Paulo: Casa do Psicólogo.

Morais, J., Mousty, P., \& Kolinsky, R. (1998). Why and how phonemeawareness helps learning to read. Em C. Hulme \& R. M. Joshi (Orgs.), Reading and spelling: development and disorders (p.127-151). Mahwah, N. J.: Lawrence Erlbaum.

Navas, A. L. G. P., \& Santos, M. T. M. (2004). Aquisição e desenvolvimento da linguagem escrita. Em M. T. M Santos \& A. L. G. P. Navas (Orgs.), Distúrbios de Leitura e Escrita: teoria e prática (pp.1-26). São Paulo: Manole.

Paula, G. R., Mota, H. B., \& Keske-Soares, M. (2005, Maio/Agosto). A terapia em consciência fonológica no processo de alfabetização. Pró-Fono: Revista de Atualização Científica, 17(2), 175-184. 
Pestun, M. S. V. (2005). Consciência fonológica no início da escolarização e o desempenho ulterior em leitura e escrita: estudo correlacional. Estudos de Psicologia - Natal, 10(3), 407-412.

Rotta, N. T. (2006). Dificuldades para a aprendizagem. Em N. T. Rotta, L. Ohlweiler \& R. S. Riesgo (Orgs.), Transtornos da Aprendizagem: Abordagem neurobiológica e multidisciplinar (pp.113-123). Porto Alegre: Artmed.

Rotta, N. T. , \& Pedroso, F. S. (2006). Transtorno da linguagem escrita-dislexia. Em N. T. Rotta, L. Ohlweiler, \& R. S. Riesgo (Orgs.), Transtorno da Aprendizagem: Abordagem neurobiológica e multidisciplinar. Porto Alegre: Artmed.
Wechsler, D. (2002). WISC-III: Escala de Inteligência Wechsler para crianças: Manual/David Wechsler ( $3^{a}$ ed.). Adaptação e Padronização de uma amostra brasileira (Vera Lúcia Marques de Figueiredo). São Paulo: Casa do Psicólogo.

Zorzi, J. L. (2003). Aprendizagem e distúrbios da linguagem escrita: questões clínicas e educacionais. Porto Alegre: Artmed.

Recebido em: 11/09/2009

Reformulado em: 30/04/2010

Aprovado em: 17/05/2010

\section{Sobre as autoras}

Magda Solange Vanzo Pestun (pestun@sercomtel.com.br)

Universidade Estadual de Londrina, Londrina - PR.

Leila Cristina Ferreira Omote (leilaomote@hotmail.com)

PSICO VIDA - Centro de Psicologia Aplicada, Londrina - PR

Déborah Cristina Málaga Barreto (deborah.barreto@londrina.pr.gov.br)

Secretaria Municipal de Educação de Londrina - PR

Tiemi Matsuo (tieme@uel.br)

Universidade Estadual de Londrina Departamento de Matemática Aplicada, Londrina - PR

\section{Correspondência}

Magda Solange Vanzo Pestun

Universidade Estadual de Londrina

Departamento de Psicologia Social e Institucional

Rodovia Celso Garcia Cid (PR 445), Km 380 Londrina - PR 